\title{
One-Pot Synthesis of Xanthene Derivatives Using Silica Supported [2-(Sulfooxy)ethyl]sulfamic Acid as a Novel and Efficient Catalyst Under Solvent-Free Condition
}

\author{
SAMI SAJJADIFAR ${ }^{1 *}$, MANOCHEHR FADAEIAN ${ }^{2}$, \\ MINA BAKHTIYARI ${ }^{1,2}$ and SOBHAN REZAYATI ${ }^{1}$ \\ ${ }^{1}$ Department of Chemistry, Payame Noor University, PO BOX 19395-4697 Tehran, Iran \\ ${ }^{2}$ Department of Applied Chemistry Qom, Branch Islamic Azad University, Qom, Iran \\ ss_sajjadifar@yahoo.com
}

Received 30 April 2013 / Accepted 7 June 2013

\begin{abstract}
An efficient and simple method for the synthesis of xanthenes derivatives is described via one-pot condensation of various aldehydes and 2-naphthol using [2-(sulfooxy)ethyl]sulfamic acid (SESA) as a novel catalyst. Different types of aromatic aldehydes were used in the reaction and in all cases the products synthesized successfully Use of easily available catalyst, time minimizing, excellent yields, simplicity of the reaction, heterogeneous system, a cleaner reaction and easy workup are the advantages of the present method.
\end{abstract}

Keywords: [2-(Sulfooxy)ethyl]sulfamic acid, Solid acid, Xanthenes derivatives, 2-Naphthol, Solventfree, Sulfonated catalyst

\section{Introduction}

Xanthenes and benzoxanthenes are an important category of organic compounds. Recently, these compounds have attracted the attention of organic and medical chemists because these compounds have biologic and medical characteristics including antiviral characteristics ${ }^{1}$, bactericide activity ${ }^{2}$, anti inflammatory activities ${ }^{3}$, have been utilized as antagonists for drug-resistant leukemia lines ${ }^{4}$ and also they have a great usage in photodynamic treatment, Also we can mention some of the applications of these compounds regarding their spectroscopic properties in laser technology ${ }^{5}$, fluorescent materials for visualization ${ }^{6}$ and these heterocyclic molecules have been widely used as dyes ${ }^{7}$. There have been multiple ways for the synthesis of xanthenes and benzoxanthene reported, one of which is the following reactions: Reaction of aryloxy magnesium halides with triethyl ortho formate ${ }^{8}$, cyclodehydration $^{9}$, cyclization of polyclic aryl triflate esters ${ }^{10}$, intermolecular phenyl carbonyl coupling reactions of benzaldehydes and acetophenones ${ }^{11}$, trapping of benzynes by phenols $^{12}$ and various reagents have been employed for the synthesis of benzoxanthenes such as amberlyst- $15^{13}$, sulfamic acid ${ }^{14}$, tungsten heteropoly acid ${ }^{15}, \mathrm{~K}_{2} \mathrm{COW}_{12} \mathrm{O}_{40} \cdot 3 \mathrm{H}_{2} \mathrm{O}^{16}$, 
molecular iodine ${ }^{17}$, silica sulfuric acid ${ }^{18}$ and boric acid ${ }^{19}$ as catalysts. However, many of these methods suffer from certain drawbacks including longer reaction times, unsatisfactory yields, low efficiency, long time period for completing these reactions, harsh reaction conditions, and using poisonous and expensive catalyst materials. In the recent years using solid acid catalysts for the synthesis of organic compounds has gained some attention. In the present research we wish to describe a new protocol for the rapid preparation of $14 \mathrm{H}$ dibenzo[a,j]xanthene derivatives using the reaction of various aldehydes (1 eq) and 2-naphthol (2 eq) catalytic amount of solid acid catalysts like using SESA in the solvent free condition and in $130{ }^{\circ} \mathrm{C}$ (Scheme 1). The results of this study are listed in Table 1. In this research, the catalytic ability of [2-(sulfooxy)ethyl]sulfamic acid was examined for conversion of aldehyde to corresponding $14 \mathrm{H}$ dibenzo[a,j]xanthenes.

In this work, [2-(sulfooxy)ethyl]sulfamic acid synthesized by eco-friendly and simple procedure, and used as highly efficient and reusable catalyst to promote the following onepot multi component organic transformations under solvent-free conditions. some benefits of this method are catalyst safety, increasing the efficiency of the products, decreasing the time of the completion of the reaction, compatibility with the environment, easy to handle, environmentally benign, presents fewer disposal problems and its compatibility.

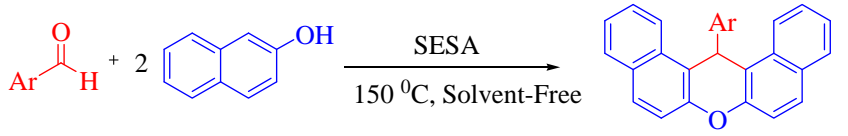

1

2

3

\section{Experimental}

Scheme 1. Synthesis of xanthenes using SESA

Products were separated and purified by different chromatographic techniques and were identified by the comparison of their IR and NMR with those reported for the authentic samples. ${ }^{1} \mathrm{H}$ and ${ }^{13} \mathrm{C}$ NMR spectra were measured (in $\mathrm{CDCl}_{3}$ solutions) on a BRUKER DRX-400 AVANCE spectrometer at 400 and $100 \mathrm{MHz}$, respectively. IR spectra of the compounds were obtained on a Perkin Elmer spectrometer version 10.03 .06 using a $\mathrm{KBr}$ disk. The progress of reaction was followed with thin-layer chromatography (TLC) using silica gel SILG/UV 254 and 365 plates. All reagents were purchased from Aldrich or Merck Fine Chemicals and were used without further purification. All products are known and compared with data literature.

\section{Preparation of [2-(sulfooxy)ethyl] sulfamic acid (SESA)}

$25 \mathrm{mmol}(1.527 \mathrm{~g})$ of amino ethanol was taken in a $250 \mathrm{~mL}$ flask and have allowed to remain at room temperature. Then, mixture of $2 \mathrm{mmol}(3.5 \mathrm{~mL})$ chloro sulfonic acid and $5 \mathrm{~mL}$ dichloromethane was added drop by drop to the flask containing amino ethanol for 4560 minutes. The reaction mixture was allowed to stand for $80 \mathrm{~min}$. All $\mathrm{HCl}$ gas evolved from the mixture. Then required amount of silica gel was added with [2-(sulfooxy)ethyl]sulfamic acid and then the mixture was washed with ether to remove the SESA. Finally, a grayish solid material was obtained in $98.3 \%$ yield.

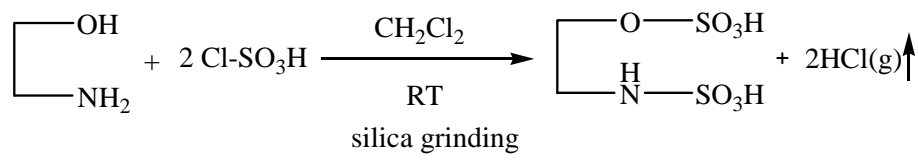

Scheme 2. Synthesis of catalyst 
General procedure for the preparation of xanthene derivates

A mixture of 2-naphthol (2 mmol), various aldehyde $(1 \mathrm{mmol})$ and [2-(sulfooxy)ethyl] sulfamic acid (15\%) in a round bottomed flask was heated on the oil bath at $130{ }^{\circ} \mathrm{C}$. The time required for each reaction is indicated in Table 1 . The reaction was followed by TLC (n-hexane:EtOAc, 20:1). Upon completion of reaction, the reaction mixture was cooled to room temperature and the catalyst was removed by filtration. The solvent was removed under vacuum, followed by column chromatography on silica gel using $n$-hexane:EtOAc, (20:1) gave the pure products. All the products were identified with milting point, ${ }^{1} \mathrm{H}$ NMR, ${ }^{13} \mathrm{C}$ NMR and FT-IR spectroscopy techniques ${ }^{20-25}$.

Table 1. Conversion of aldehyde to xanthene using $\mathrm{SESA} / \mathrm{SiO}_{2}$ under solvent-free condition

\begin{tabular}{|c|c|c|c|c|}
\hline S. No. & Product & Time, min & $\begin{array}{c}\text { Yield, } \\
\%^{\mathrm{a}}\end{array}$ & $\begin{array}{l}\text { m.p Found, }{ }^{\circ} \mathrm{C} \\
\text { m.p [Lit.], }{ }^{\circ} \mathrm{C}\end{array}$ \\
\hline 1 & & 170 & 92 & $\begin{array}{l}180-183 \\
183[20]\end{array}$ \\
\hline 2 & & 35 & 90 & $\begin{array}{l}294-297 \\
296[20]\end{array}$ \\
\hline 3 & & 20 & 85 & $\begin{array}{l}258-260 \\
259[20]\end{array}$ \\
\hline 4 & & 10 & 73 & $\begin{array}{c}210-212 \\
210-211[21]\end{array}$ \\
\hline 5 & & & & $\begin{array}{c}199-201 \\
202-203[21]\end{array}$ \\
\hline & & 45 & 93 & \\
\hline
\end{tabular}

Contd... 
6<smiles>O=[N+]([O-])c1ccc(C2c3c(ccc4ccccc34)Oc3ccc4ccccc4c32)cc1</smiles>

20

76

310-313

310-311[21]

7<smiles>Cc1ccc(C2c3c(ccc4ccccc34)Oc3ccc4ccccc4c32)cc1</smiles>

10

83

195-198

227-228[21]

8<smiles>Clc1ccc(C2c3c(ccc4ccccc34)Oc3ccc4ccccc4c32)cc1</smiles>

25

90

286-289

287-288[21]

9<smiles>Brc1ccc(C2c3c(ccc4ccccc34)Oc3ccc4ccccc4c32)cc1</smiles>

35

96

294-296

295-296[21]

10<smiles>O=Cc1ccc(C2c3c(ccc4ccccc34)Oc3ccc4ccccc4c32)cc1</smiles>

85

78

251-253

252-254[22]

11<smiles>Oc1cccc(C2c3c(ccc4ccccc34)Oc3ccc4ccccc4c32)c1</smiles>

200

70

260-262

261-263[23]

Contd... 
12<smiles>CN(C)c1ccc(C2c3c(ccc4ccccc34)Oc3ccc4ccccc4c32)cc1</smiles>

13<smiles>Clc1cccc(C2c3c(ccc4ccccc34)Oc3ccc4ccccc4c32)c1Cl</smiles>

14<smiles>Clc1ccccc1C1c2c(ccc3ccccc23)Oc2ccc3ccccc3c21</smiles>

15<smiles>Oc1ccc(C2c3c(ccc4ccccc34)Oc3ccc4ccccc4c32)cc1</smiles>

16<smiles>O=[N+]([O-])c1ccc(C2c3c(ccc4ccccc34)Oc3ccc4ccccc4c32)cc1Cl</smiles>

17<smiles>COc1ccc(C2c3c(ccc4ccccc34)Oc3ccc4ccccc4c32)cc1</smiles>

18<smiles>COc1ccc(OC)c(C2c3c(ccc4ccccc34)Oc3ccc4ccccc4c32)c1</smiles>

30

25

20

89

95

93

227-229

68

232-234

282-284

209-212

140-143

140 [24]

15

88

168-180

169[25]

25

90
168[25] 


\section{Results and Discussion}

[2-(Sulfooxy)ethyl]sulfamic acid (SESA) was easily prepared by addition of chlorosulfonic acid to 2-aminoethanol under $\mathrm{N}_{2}$ atmosphere at room temperature. This reaction was easy and clean, because $\mathrm{HCl}$ gas was evolved from the reaction vessel immediately (Scheme 1). IR spectrum showed the characteristic peak of S-O group at $450-600 \mathrm{~cm}^{-1}, \mathrm{~S}=\mathrm{O}$ at $1000-1200 \mathrm{~cm}^{-1}$ and broad peak at $2900-3600 \mathrm{~cm}^{-1}$ related to the $\mathrm{OH}$ of $\mathrm{SO}_{3} \mathrm{H}$ groups. Moreover, the two peaks were observed at $1085 \mathrm{~cm}^{-1}$ and $1285 \mathrm{~cm}^{-1}$ correspond to vibrational modes of $\mathrm{N}-\mathrm{SO}_{2}$ bond.

The IR spectrum of the catalyst showed a broad peak at 3100-3400 $\mathrm{cm}^{-1} .{ }^{1} \mathrm{H}$ NMR spectrum of SESA, showed the unmistaken acidic hydrogens $\left(\mathrm{SO}_{3} \mathrm{H}\right)$ peaks at 12.86 and 11.96 and peak of $\mathrm{NH}$ group at 9.806, peak of $\mathrm{O}-\mathrm{CH}_{2}$ group at 3.417-3.442, $\mathrm{N}-\mathrm{CH}_{2}$ group at 3.809-3.840 and peak of $\mathrm{NH}$ group at 9.806 . These spectrums and data confirmed that this catalyst was exactly synthesized.

In continuation of our study on application of solid acid ${ }^{26-35}$, we report the synthesis of $14 \mathrm{H}$ dibenzo[a,j]xanthene derivatives in the presence of a catalytic amount of [2-(sulfooxy)ethyl] sulfamic acid (SESA) as a novel, efficient and recycle eco-friendly organo solid acid catalyst in solvent-free condition by a simple, efficient and high-yielding method (Scheme 1). The reaction conditions were optimized on the basis of the catalysts and temperature (Table 2 and Table 3). In recent years, solvent-free organic reactions have caused great interests, which have many advantages such as high efficiency and selectivity, separation and purification, mild reaction conditions and to benefit industry as well as environment ${ }^{36-39}$. The condensation reaction was studied by examining the amount of catalyst in the reaction involving $1 \mathrm{mmol}$ of benzaldehyde and $2 \mathrm{mmol}$ of 2-naphthol to afford the products under solvent free conditions at $130{ }^{\circ} \mathrm{C}$. The best result was obtained with $15 \mathrm{~mol} \%$ catalyst. To determine the role of [2-(sulfooxy) ethyl]sulfamic acid, the model reaction was carried out in the absence of catalyst at room temperature under solvent-free condition. The desired product was not obtained after 720 min (Table 2). As it can be seen in Table 1, excellent yield and shorter reaction time were obtained when the reaction was carried out in the presence of $15 \mathrm{~mol} \%$ of the catalyst at $130{ }^{\circ} \mathrm{C}$.

Table 2. Catalyst optimization in the reaction of benzaldehyde with 2-naphthol

\begin{tabular}{cccc}
\hline S. No. & Molar ratio of SESA $/ \mathrm{SiO}_{2}, \%$ & Time, min & Yield\% $^{\mathrm{a}}$ \\
\hline 1 & - & 720 & 0 \\
2 & 3 & 180 & 88 \\
3 & 5 & 80 & 87 \\
4 & 10 & 47 & 83 \\
5 & 15 & 45 & 94 \\
6 & 20 & 39 & 83 \\
\hline \multicolumn{3}{c}{${ }^{a}$ Isolated yield }
\end{tabular}

Table 3. Optimization of temperature in presence of catalyst (15 mol\%)

\begin{tabular}{cccc}
\hline S. No. & Temperature & Time, min & Yield, \% \\
\hline 1 & 100 & 130 & 80 \\
2 & 110 & 110 & 85 \\
3 & 120 & 40 & 93 \\
4 & 130 & 25 & 95 \\
5 & 130 & 37 & 94 \\
\hline
\end{tabular}

In order to further validate our work, the current protocol was compared with the data in the literature based on the catalysts content, temperature, reaction time and percentage yields (Table 4). Although, some of the additives catalyzed the reaction at lower temperature, they required longer reaction times and or higher catalyst content. Short-reaction time $(10 \mathrm{~min})$, mild reaction condition, and environmentally benign catalyst are distinct advantages of the current methodology. 
Table 4. Comparison of the catalytic efficiency of SESA with some reported catalysts in synthesis of dibenzoxanthenes

\begin{tabular}{ccccc}
\hline S. No. & Catalyst & Time, h & Condition & References \\
\hline 1 & $\mathrm{SiO}_{2} / \mathrm{HO}_{3} \mathrm{SNHCH}_{2} \mathrm{CH}_{2} \mathrm{OSO}_{3} \mathrm{H}$ & $10-400 \mathrm{~min}$ & solvent free, $130{ }^{\circ} \mathrm{C}$ & This work \\
2 & $\mathrm{FeCl}_{3}$ & 10 & solvent free, $100{ }^{\circ} \mathrm{C}$ & {$[40]$} \\
3 & $\mathrm{Yb}(\mathrm{OTf})_{3}$ & $3-7$ & [bipy]BF4, $110{ }^{\circ} \mathrm{C}$ & {$[41]$} \\
4 & Sulfamic acid & $6-12$ & solvent free, $125^{\circ} \mathrm{C}$ & {$[14]$} \\
5 & $p$-Toluene sulfonic acid & $15-24$ & 1,2 -Dichloroethane & {$[42]$} \\
6 & $p$-Toluene sulfonic acid & $2.5-6$ & solvent-free, $125{ }^{\circ} \mathrm{C}$ & {$[42]$} \\
7 & $\mathrm{Sc}\left[\mathrm{N}_{\left.\left(\mathrm{SO}_{2} \mathrm{C}_{8} \mathrm{~F}_{17}\right)_{2}\right]_{3}}\right.$ & $2-7$ & perfluorodecalin, $110^{\circ} \mathrm{C}$ & {$[43]$} \\
8 & $\mathrm{I}_{2}$ & $2-5$ & solvent free, $90^{\circ} \mathrm{C}$ & {$[17]$} \\
9 & Alum & $3-4$ & Water, $100{ }^{\circ} \mathrm{C}$ & {$[44]$} \\
10 & SelectfluorTM & $6-12$ & solvent free, $125^{\circ} \mathrm{C}$ & {$[20]$} \\
\hline
\end{tabular}

${ }^{a}$ Reflux temperature. ${ }^{b}$ 1-(Chloromethyl)-4-fluoro-1,4-diazoniabicyclo[2.2.2] octane-bis(tetrafluoroborate)

Suggested reaction mechanism pathway of the synthesis of dibenzoxanthenes using SESA presented in Scheme 3. Activation of the carbonyl group of aldehyde by [2-(sulfooxy)ethyl] sulfamic acid $\left(\mathrm{SiO}_{2} / \mathrm{HO}_{3} \mathrm{SNHCH}_{2} \mathrm{CH}_{2} \mathrm{OSO}_{3} \mathrm{H}\right)$, facilitates nucleophilic attack of 2-naphthol and formation of the corresponding carbocation in the first step. This carbocation was then transformed to an aryl-methanebisnaphthol in the second step, and ultimately it was converted to the desired product via dehydration of bis(naphtholyl)methane species.

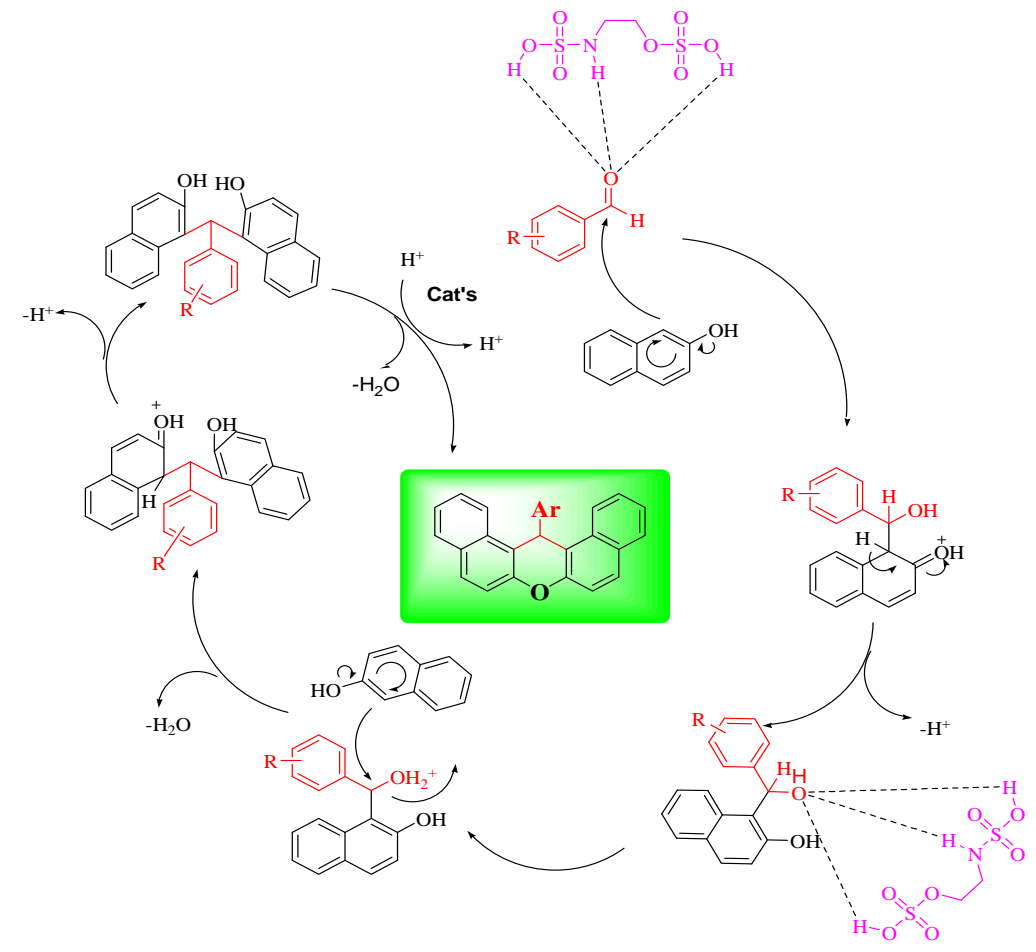

Scheme 3. Suggested reaction pathway for the catalytic synthesis of dibenzoxanthenes

Ease of recycling of the catalyst is one of the most advantages of our method. When the reaction was complete, the product was extracted by chloroform and the residue was dried. 
Solvent was removed and recycled catalyst was reused in the next reaction. For the synthesis of xanthenes, no significant loss of the product yield was observed when SESA catalyst was used after five times recycling (Table 5).

Table 5. Recovery and reusable of catalyst

\begin{tabular}{ccc}
\hline S.No. & $\begin{array}{c}\text { Thiocyanation } \\
\text { reaction }\end{array}$ & Yield,\% \\
\hline 1 & First & 94 \\
2 & Second & 92 \\
3 & Third & 90 \\
4 & Forth & 90 \\
5 & Fifth & 89 \\
\hline
\end{tabular}

\section{Conclusion}

We have developed a simple, efficient and for the synthesis of xanthenes using silica supported [2-(sulfooxy)ethyl]sulfamic acid under solvent-free conditions. This simple method is important from both environmental and economic viewpoints as it produces little waste and also the catalyst can be recovered from the reaction mixtures and reused. Offers advantages method including simplicity of operation, simple experimental procedure and non-toxicity of the reagent, easy work-up, time minimizing and high yields of products. The procedure is very simple and can be used as an alternative to the existing procedures.

\section{Acknowledgment}

The authors gratefully acknowledged for partial support of this work by Payame Noor University (PNU) of Ilam, Iran.

\section{References}

1. Ion R M, Frackowiak D, Planner A and Wiktorowicz K, Acta Biochim Pol., 1998, 45(3), 833-845.

2. $\quad$ Hideu T, Chem Abstr., 1981, 95, 80922, Jpn., Tokkyo Koho JP 56005480, 1981.

3. Jamison J M, Krabill K, Hatwalkar A, Elizabeth Jamison and Chun-che Tsai, Cell Biol Int Rep., 1990, 14(12), 1075-1084; DOI:10.1016/0309-1651(90)90015-Q.

4. Saint-Ruf G, Huynh-Trong-Hieu and Poupelin J P, Naturwiss., 1975, 62(12), 584585; DOI:10.1007/BF01166986.

5. $\quad$ Sirkecioglu O, Talinli N and Akar A, J Chem Res (S), 1995, 502-506.

6. Knight C G and Stephens T, Biochem J., 1989, 258(3), 683-687.

7. Bhowmik B B and Ganguly P, Spectrochim Acta A, 2005, 61(9), 1997-2003; DOI:10.1016/j.saa.2004.07.031.

8. Casiraghi G, Casnati G and Cornia M, Tedrahedron Lett., 1973, 14(9), 679-682; DOI:10.1016/S0040-4039(00)72432-4.

9. Bekaert A, Andrieux J and Plat M, Tedrahedron Lett., 1992, 33(20), 2805-2806; DOI:10.1016/S0040-4039(00)78863-0.

10. Wang J Q and Harvey G R, Tetrahedron, 2002, 58(29), 5927-5931; DOI:10.1016/S0040-4020(02)00534-3.

11. Kuo C W and Fang J M, Synth Commun., 2001, 31, 877-892.

12. Knignt D W and Little P B, Synlett., 1998, 10, 1141-1143.

13. Ko S and Yao C F, Tedraherdon Lett., 2006, 47(50), 8827-8829;

DOI:10.1016/j.tetlet.2006.10.072. 
14. Rajitha B, Sunil Kumar B, Thirupathi Reddy Y, Narsimha Reddy P and Sreenivasulu N, Tetrahedron Lett., 2005, 46(50), 8691-8693; DOI:10.1016/j.tetlet.2005.10.057.

15. Amini M M, Seyyedhamzeh M and Bazgir A, Appl Catal A Gen., 2007, 323, 242-245; DOI:10.1016/j.apcata.2007.02.016.

16. Nagrapu L, Kantevari S, Mahankhali V C and Apuri S, Catal Commun., 2007, 8(8), 1173-1177. DOI:10.1016/j.catcom.2006.11.003.

17. Das B, Ravikanth B, Ramu R, Laxminarayana K and Rao B V, J Mol Catal A Chem., 2006, 255(1-2), 74-77; DOI:10.1016/j.molcata.2006.04.007.

18. Seyyedhamzeh M, Mirzaei P and Bazgir A, Dyes Pigm., 2008, 76(3), 836-839; DOI:10.1016/J.DYEPIG.2007.02.001.

19. Karimi-Jaberi Z and Keshavarzi M, Chin Chem Lett., 2010, 21(5), 547-549; DOI:10.1016/J.CCLET.2010.01.014.

20. Kumar P S, Sunil Kumar B, Rajitha B, Narsimha Reddy P, Sreenivasulu N and Thirupathi Reddy Y, ARKIVOC., 2006, xii, 46-50.

21. Kumar R, Nandi G C, Verma R K and Singh M S, Tetrahedron Lett., 2010, 51(2), 442-445; DOI:10.1016/j.tetlet.2009.11.064.

22. Safaei-Ghomi J, Ghasemzadeh M A and Mehrabi M, Scientia Iranica C., 2013, 20(3), 549-554; DOI: 10.1016/j.scient.2012.12.037.

23. Kantevari S, Venu Chary M A, Rudra Das A P, Vuppalapati S V N and Lingaiah N, Catal Commun., 2008, 9(7), 1575-1578. DOI:10.1016/j.catcom.2008.01.003.

24. Madhav J V, Kuarm B S and Rajitha B, ARKIVOC., 2008, (ii), 204-209.

25. Shaterian H R, Ghashang M and Mir N, ARKIVOC., 2007, (xv), 1-10.

26. Zolfigol M A, Khazaei A, Vahedi H, Mokhlesi M, Hoshang V, Sajjadifar S and Pirveysian M, Phosphorus, Sulfur Silicon Related Elements., 2012, 187(3), 295-304; DOI:10.1080/10426507.2011.610846.

27. Khazaei A, Zolfigol M A, Mokhlesi M, Derakhshan Panah F and Sajjadifar S, Helv Chim Acta, 2012, 95(1), 106-114; DOI:10.1002/hlca.201100244.

28. Zolfigol M A, Vahedi H, Massoudi A, Sajjadifar S, Louie O and Javaherneshan N, Clin Biochem., 2011, 44(13), S219; DOI:10.1016/j.clinbiochem.2011.08.973.

29. Sajjadifar S, Am J Org Chem., 2012, 2(5), 116-121; DOI:10.5923/j.ajoc.20120205.02.

30. Sajjadifar S, Rezaee Nezhad E and Darvishi G, J Chem., 2013, 2013 ID 834656, 6 pages; DOI:10.1155/2013/834656.

31. Sajjadifar S, Int J ChemTech Res., 2013, 5(1), 385-389.

32. Sajjadifar S, Zolfigol M A, Chehardoli G, Miri S and Moosavi P, Int J ChemTech Res., 2013, 5(1), 422-429.

33. Rezaee Nezhad E, Heidarizadeh F, Sajjadifar S and Abbasi Z, J Petro Eng., 2013, 2013(203036), 5 pages (http://dx.doi.org/10.1155/2013/203036).

34. Sajjadifar S and Louie O, J Chem., 2013, 2013: ID 674946, 6 pages (http://dx.doi.org/10.1155/2013/674946).

35. Sajjadifar S, Mirshokraie S A, Javaherneshan N and Louie O, Am J Org Chem., 2012, 2(2), 1-6.

36. Tayebee $\mathrm{R}$ and Tizabi S H, Chin J Catal., 2012, 33(4-6), 962-969; DOI:10.1016/S1872-2067(11)60387-2.

37. Fu G Y, Huang Y X, Chen X G and Liu X L, J Chin Chem Soc., 2009, 56, 381-385; DOI:10.1002/jccs.200900055.

38. Dabiri M, Azimi S C and Bazgir A, Chem Papers, 2008, 62(5), 522-526; DOI:10.2478/s11696-008-0050-y. 
39. Mohammadi Ziarani G, Badiei A R and Azizi M, Scientia Iranica C., 2011, 18(3), 453-457; DOI:10.1016/j.scient.2011.05.008.

40. Wang B, Li P H, Zhang Y and Wang L, Chin J Chem., 2010, 28(12), 2463-2468; DOI:10.1002/cjoc.201190022.

41. Su W, Yang D, Jin C and Zhang B, Tetrahedron Lett., 2008, 49(21), 3391-3394; DOI:10.1016/j.tetlet.2008.03.124.

42. Khosropour A R, Khodaei M M and Moghannian H, Synlet., 2005, 2005(6), 09550958; DOI:10.1055/s-2005-864837.

43. Hong M and Cai C, J Fluor Chem., 2009, 130(10), 989-992;

DOI:10.1016/j.jfluchem.2009.06.013.

44. Dabiri M, Baghbanzadeh M, Shakouri-Nikcheh M and Arzroomchilar E, Bioorg Med Chem Lett., 2008, 18(1), 436-438; DOI:10.1016/j.bmcl.2007.07.008 